\title{
Therapeutic Decision Making in Hepatocellular Carcinoma According to Age and Child-Pugh Class: A Nationwide Cohort Analysis in South Korea
}

\author{
Sunmin Park $\mathbb{D}^{1},{ }^{1}$ Chai Hong Rim $\mathbb{D}^{1},{ }^{1}$ Young Kul Jung $\mathbb{D}^{2},{ }^{2}$ and Won Sup Yoon $\mathbb{D}^{1}$ \\ ${ }^{1}$ Department of Radiation Oncology, Korea University Ansan Hospital, Ansan, Gyeonggi-do, Republic of Korea \\ ${ }^{2}$ Division of Gastroenterology and Hepatology, Department of Internal Medicine, Korea University Ansan Hospital, Ansan, \\ Gyeonggi-do, Republic of Korea
}

Correspondence should be addressed to Won Sup Yoon; irionyws@korea.ac.kr

Received 12 November 2020; Revised 18 December 2020; Accepted 22 December 2020; Published 5 January 2021

Academic Editor: Alessandro Granito

Copyright (C) 2021 Sunmin Park et al. This is an open access article distributed under the Creative Commons Attribution License, which permits unrestricted use, distribution, and reproduction in any medium, provided the original work is properly cited.

Background. We sought to analyze the preferred treatment modality by age and liver function in South Korea. Methods. The Korean Liver Cancer Study Group randomly extracted the data of patients with hepatocellular carcinoma (HCC) enrolled in the Korean Central Cancer Registry from 2008 to 2014 from approximately 50 hospitals nationwide. After excluding distant and lymphatic metastases, the treatment preference for patients with a single lesion (excluding PVT (portal vein thrombosis), hepatic vessels, and bile duct invasion) and with PVT was evaluated in 7559 patients. Patients were grouped by age, and baseline liver function was divided based on the Child-Pugh class (CPC) A, B, and C. Results. For a single HCC, the majority of patients selected transarterial therapy as the initial treatment, followed by surgical resection and local ablative therapy. The surgical resection rate decreased significantly with age $(p<0.001)$, and the transarterial therapy rate significantly increased $(p<0.001)$. For CPC C, liver transplantation was significantly increased to $11.5 \%$, and $36.3 \%$ of patients received no treatment. In HCC with PVT, the transarterial therapy rate was the highest, followed by the rate of abandonment of treatment. The proportion of no treatment significantly increased with age $(p<0.001)$. In CPC C, transarterial therapy and systemic therapy were attempted in $15.4 \%$ and $5.8 \%$ of patients, respectively. Conclusions. Age and liver function have a significant impact on the therapeutic decision-making of HCC patients in Korea. In unfavorable conditions, surgical resection was less favored in patients with single tumors, and no treatment was preferred in patients with PVT.

\section{Introduction}

Various guidelines for hepatocellular carcinoma (HCC) currently recommend standard and alternative treatment methods according to the tumor stage using characteristics such as tumor size, number of tumors, and degree of invasion of the major structures [1-6]. Patients with very earlyto early-stage HCC should be considered for potentially curative options such as surgical resection, radiofrequency ablation (RFA), and transplantation. In patients with portal vein invasion belonging to the advanced stage (Barcelona clinic liver cancer (BCLC) C), systemic treatments including sorafenib are recommended as the standard treatment. Although the treatment of HCC is suggested by several guidelines as described above, various situations make HCC difficult to treat.

Together with the aging of the population in South Korea, the number of older people with cancer has increased considerably in the last decade [7]. The most common cause of HCC in East Asian countries, including China and Korea, is chronic hepatitis B virus (HBV) infection; patients in these countries tend to be diagnosed with more advanced disease $[8,9]$, which eventually leads to a poor Child-Pugh class (CPC). According to recent statistics in South Korea, more than 1 in 4 HCC patients are vulnerable; in that, $24.8 \%$ of cases occurred in people in their 70 s [10] and $28.4 \%$ developed the CPC $B$ or $C$ [11]. However, many clinical trials exclude these groups of geriatrics, as well as those with 
unfavorable liver function, and evidence to guide treatment of these patients remains limited. In this situation, strategies for vulnerable HCC patients can be suggested by not only the guidelines but also the previous experience of actual practice.

Korean trends in treatment have not been previously published. Based on the cohort of the HCC registry project, this study was designed to investigate the preferred treatment methods in actual clinical practice. We specifically focused on the age and basal liver status of patients.

\section{Materials and Methods}

2.1. Database Source. Since 1980, the Korean Ministry of Health and Welfare has funded the Korean Central Cancer Registry (KCCR). The Korean Liver Cancer Study Group (KLCSG) and the National Cancer Center extracted HCC patient records from the KCCR to settle the mother population, which have been assigned codes of C22.0 according to the ICD-10. The studies performed by the KLCSG between 2008 and 2014 in South Korea were randomly selected among all hospitals nationwide that registered HCC patients in the KCCR. At least, one hospital was selected from all 16 administrative districts in South Korea, and the probability proportional extraction method, which is more likely to select hospitals with a large number of registered patients, was used. Through the three projects, the records of 15,078 patients who were initially diagnosed with HCC between 2008 and 2014 were sampled. Data on dates and causes of mortality were obtained from the Korean Statistical Information Service. The date of the first diagnosis of HCC was provided in the KCCR data.

2.2. Study Cohort. Of the total 15078 patients, we excluded patients under 18 years of age with initial lymph node metastases and/or distant metastases. For the analyses of single lesions, portal vein thrombosis (PVT), hepatic vessels, and bile duct invasive patients were additionally excluded. A total of 7559 patients were enrolled and analyzed, and subcohorts of single lesion and PVT were constructed. Age groups were classified as $<59,60-69$, and $\geq 70$ years. Baseline liver function was divided into CPC A, B, or C. The groups of single lesions were divided into $\leq 2 \mathrm{~cm}$ and $>2 \mathrm{~cm}$ by the size of the tumor, and patients with PVT were analyzed in total. The preference of treatment was analyzed by the age group and baseline liver function status. Treatments were classified into surgical resection, liver transplantation, local ablative therapy (including mainly RFA, alcohol injection, and other local ablation), transarterial therapy (including mainly TACE with gelfoam, beads and lipiodol without gelfoam, transarterial chemoinfusion, and radioembolization), systemic chemotherapy (sorafenib and other systematic therapy), radiation therapy (RT), and no treatment according to the initial presentation of treatment.

2.3. Outcome Assessment and Statistical Analysis. The changes in treatment patterns were assessed. A Chi-square test was conducted to analyze the difference in treatment preference in terms of age and liver function. All statistical tests were performed using SPSS (version 22; IBM, Armonk, NY).

2.4. Ethical Consideration. The data source of the present study is public open data without personal identification information from the KCCR. Institutional review board approval was waived; in all other respects, we recognized and adhered to the World Medical Association Declaration of Helsinki.

\section{Results}

3.1. Patient Characteristics. The median age of the patients was 60.0 years (range, 21-98), and 5838 patients $(77.2 \%)$ were men in a total of 7559 patients. CPC of $A, B$, and $C$ were seen in 5855 (77.5\%), 1422 (18.8\%), and 282 (3.7\%) patients, respectively (Table 1). Among them, our single lesion and PVT-positive cohorts were satisfied by 4633 patients and 625 patients, respectively. CPC B patients accounted for 667 (14.4\%) patients in single lesion and 235 (38.6\%) patients in PVT-positive cohorts. In all patient cohorts with CPC $B$, we analyzed treatment patterns in 1394 patients excluding 28 with missing data, and $55.2 \%$ of patients selected transarterial therapy as the initial treatment, followed by no treatment $(24.7 \%)$ and systemic chemotherapy (10.6\%). In a single lesion cohort with CPC B, transarterial therapy accounted for $54.4 \%$, followed by local ablative therapy $(17.7 \%)$ and no treatment (16.0\%). Of the PVT-positive patients with CPC B, the proportion of patients with 'no treatment' was $46.8 \%$, followed by transarterial therapy (34.5\%) and systemic chemotherapy (14.5\%).

3.2. Single Lesion. Of the total 4633 single lesions, $43.6 \%$ were $\leq 2 \mathrm{~cm}$ and $56.4 \%$ were $>2 \mathrm{~cm}$. In the single lesion group, $39.1 \%$ of patients selected transarterial therapy as the initial treatment, followed by surgical resection (31.4\%) and local ablative therapy (19.8\%). Compared to the standard management (surgical resection or local ablation therapy) in most guidelines, transarterial therapy is preferred in patients $\geq 70$ years of age and with CPC $B$ and $C$ (Table 2), and RT had the lowest rate in single-lesion patients $(0.5 \%)$. In terms of age, the proportion of surgical resection significantly decreased (39.6\% vs. $28.9 \%$ vs. $18.0 \%$; $<59$ vs. $60-69$ vs. $\geq 70 ; p<0.001$ ) and the proportion of transarterial therapy significantly increased $(33.6 \%$ vs. $41.0 \%$ vs. $48.0 \%$; $<59$ vs. $60-69$ vs. $\geq 70$; $p<0.001)$. In terms of the CPC, the proportion of surgical resection significantly decreased $(36.3 \%$ vs. $7.9 \%$ vs. $0.9 \% ; A$, $B$, and $C ; p<0.001)$, while liver transplantation significantly increased with CPC $(0.6 \%$ vs. $1.5 \%$ vs. $11.5 \% ; A, B$, and $C$; $p<0.001)$. Local ablative therapy showed no significant difference with respect to the age group (19.4\% vs. $21.4 \%$ vs. $18.5 \%$; $<59$ vs. $60-69$ vs. $\geq 70 ; p=0.784)$, and a marginal difference was seen for CPC (20.2\% vs. $17.7 \%$ vs. $16.8 \% ; A, B$, and $C ; p=0.094)$. Local ablative therapy was preferred to surgical resection regardless of age and CPC in tumors $\leq 2 \mathrm{~cm}$, and surgical resection was preferred to local ablation therapy in tumors $>2 \mathrm{~cm}$ in all age groups and CPC $A$ and $B$ (Figures 1 and 2). In patients with tumors $>2 \mathrm{~cm}$, the proportion of no 
Table 1: Patient characteristics $(n=7559)$.

\begin{tabular}{|c|c|c|c|}
\hline Variables & $\begin{array}{c}\text { All patients } \\
n=7559\end{array}$ & $\begin{array}{c}\text { Single tumor } \\
n=4633\end{array}$ & $\begin{array}{c}\text { PVT-positive tumor } \\
n=625\end{array}$ \\
\hline \multicolumn{4}{|l|}{ Age } \\
\hline Median (range) & $60(21-98)$ & $61(22-91)$ & $57(28-92)$ \\
\hline$\leq 59$ & $3577(47.3 \%)$ & $2182(47.1 \%)$ & $366(58.6 \%)$ \\
\hline $60-69$ & $2180(28.8 \%)$ & $1355(29.2 \%)$ & $145(23.2 \%)$ \\
\hline$\geq 70$ & $1802(23.8 \%)$ & $1096(23.7 \%)$ & $114(18.2 \%)$ \\
\hline \multicolumn{4}{|l|}{ Sex } \\
\hline Male & $5838(77.2 \%)$ & $3471(74.9 \%)$ & $527(84.3 \%)$ \\
\hline Female & $1721(22.8 \%)$ & $1162(25.1 \%)$ & $98(15.7 \%)$ \\
\hline \multicolumn{4}{|l|}{ Child-Pugh class } \\
\hline A & $5855(77.5 \%)$ & $3850(83.1 \%)$ & $327(52.3 \%)$ \\
\hline B & $1422(18.8 \%)$ & $667(14.4 \%)$ & $241(38.6 \%)$ \\
\hline $\mathrm{C}$ & $282(3.7 \%)$ & $116(2.5 \%)$ & $57(9.1 \%)$ \\
\hline Hepatitis B & $4507(59.6 \%)$ & $1736(37.5 \%)$ & $413(66.1 \%)$ \\
\hline Hepatitis C & $983(13.0 \%)$ & $581(12.5 \%)$ & $69(11.0 \%)$ \\
\hline Non-B, non-C & $267(3.5 \%)$ & $165(3.6 \%)$ & $17(2.7 \%)$ \\
\hline \multicolumn{4}{|c|}{ ECOG performance status } \\
\hline 0 & $4310(57.0 \%)$ & $2827(61.0 \%)$ & $252(40.3 \%)$ \\
\hline 1 & $798(10.6 \%)$ & $395(8.5 \%)$ & $127(20.3 \%)$ \\
\hline 2 & $154(2.0 \%)$ & $51(1.1 \%)$ & $38(6.1 \%)$ \\
\hline 3 & $55(0.7 \%)$ & $12(0.3 \%)$ & $23(3.7 \%)$ \\
\hline 4 & $37(0.5 \%)$ & $8(0.2 \%)$ & $10(1.6 \%)$ \\
\hline NA & $2205(29.2 \%)$ & $1340(28.9 \%)$ & $175(28.0 \%)$ \\
\hline \multicolumn{4}{|l|}{ Tumor size $(\mathrm{cm})$} \\
\hline$\leq 2 \mathrm{~cm}$ & $2746(36.3 \%)$ & $2018(43.6 \%)$ & $53(8.5 \%)$ \\
\hline$>2 \mathrm{~cm}$ & $4813(63.7 \%)$ & $2615(56.4 \%)$ & $572(91.5 \%)$ \\
\hline \multicolumn{4}{|c|}{ Number of tumors } \\
\hline$\leq 4$ & $6511(86.1 \%)$ & $4633(100.0 \%)$ & $204(32.6 \%)$ \\
\hline$>4$ & $1048(13.9 \%)$ & $0(0.0 \%)$ & $421(67.4 \%)$ \\
\hline
\end{tabular}

ECOG, Eastern Cooperative Oncology Group; PVT, portal vein tumor thrombosis; NA, not available.

TABle 2: Treatment pattern change by age and the Child-Pugh classification in single lesions.

\begin{tabular}{|c|c|c|c|c|}
\hline \multirow{2}{*}{ Treatment $n=4601$} & \multicolumn{4}{|c|}{ Age (years) } \\
\hline & $\leq 59$ & $60-69$ & $\geq 70$ & $p$ value \\
\hline Surgical resection & $859(39.6 \%)$ & $390(28.9 \%)$ & $194(18.0 \%)$ & $<0.001$ \\
\hline Liver transplantation & $35(1.6 \%)$ & $12(0.9 \%)$ & $0(0.0 \%)$ & $<0.001$ \\
\hline Local ablative therapy & $422(19.4 \%)$ & $289(21.4 \%)$ & $200(18.5 \%)$ & 0.784 \\
\hline Transarterial therapy & $729(33.6 \%)$ & $553(41.0 \%)$ & $518(48.0 \%)$ & $<0.001$ \\
\hline Systemic chemotherapy & $7(0.3 \%)$ & $6(0.4 \%)$ & $7(0.6 \%)$ & 0.188 \\
\hline Radiation therapy & $7(0.3 \%)$ & $12(0.9 \%)$ & $4(0.4 \%)$ & 0.525 \\
\hline No treatment & $112(5.2 \%)$ & $88(6.5 \%)$ & $157(14.5 \%)$ & $<0.001$ \\
\hline \multirow{2}{*}{$n=4601$} & \multicolumn{4}{|c|}{ Child-Pugh classification } \\
\hline & $A$ & $B$ & C & $p$ value \\
\hline Surgical resection & $1390(36.3 \%)$ & $52(7.9 \%)$ & $1(0.9 \%)$ & $<0.001$ \\
\hline Liver transplantation & $24(0.6 \%)$ & $10(1.5 \%)$ & $13(11.5 \%)$ & $<0.001$ \\
\hline Local ablative therapy & $776(20.2 \%)$ & $116(17.7 \%)$ & $19(16.8 \%)$ & 0.094 \\
\hline Transarterial therapy & $1405(36.7 \%)$ & $356(54.4 \%)$ & $39(34.5 \%)$ & $<0.001$ \\
\hline Systemic chemotherapy & $14(0.4 \%)$ & $6(0.9 \%)$ & $0(0.0 \%)$ & 0.282 \\
\hline Radiation therapy & $13(0.3 \%)$ & $10(1.5 \%)$ & $0(0.0 \%)$ & 0.010 \\
\hline No treatment & $211(5.5 \%)$ & $105(16.0 \%)$ & $41(36.3 \%)$ & $<0.001$ \\
\hline
\end{tabular}

treatment increased significantly to $18.1 \%$ in cases $\geq 70$ years, $22.1 \%$ in $\mathrm{CPC}$ B, and $42.9 \%$ in CPC C (Figures 1 and 2).

3.3. PVT-Positive Cases. Of the total 625 patients, $44.1 \%$ of patients selected transarterial therapy as the initial treatment, followed by no treatment (33.7\%) and systemic chemotherapy (13.7\%). RT was selected by 3.0\% PVT-positive patients. While the proportion of transarterial therapy decreased significantly with aggravated CPC (56.0\% vs. $34.5 \%$ vs. $15.4 \%$; $A, B$, and $C$; $p<0.001$ ), the impact of age on the choice of transarterial therapy was minimal $(p=0.262)$ 


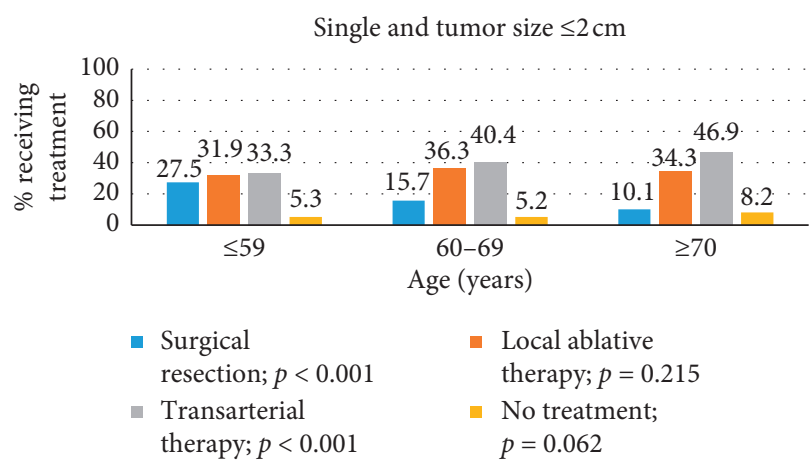

(a)

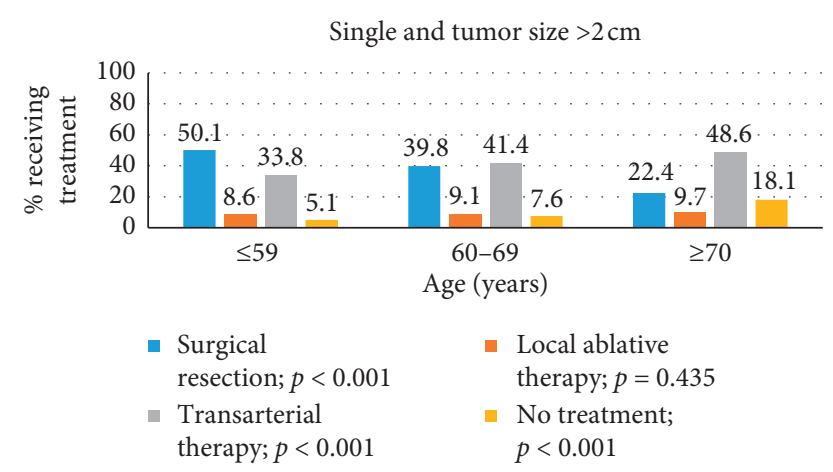

(b)

Figure 1: Proportion of the treatments performed for a single lesion according to age group. (a) Tumor size $\leq 2 \mathrm{~cm}$ for surgical resection $(p<0.001)$, local ablative therapy $(p=0.215)$, transarterial therapy $(p<0.001)$, and no treatment $(p=0.062)$. (b) Tumor size $>2 \mathrm{~cm}$ for surgical resection $(p<0.001)$, local ablative therapy $(p=0.435)$, transarterial therapy $(p<0.001)$, and no treatment $(p<0.001)$.

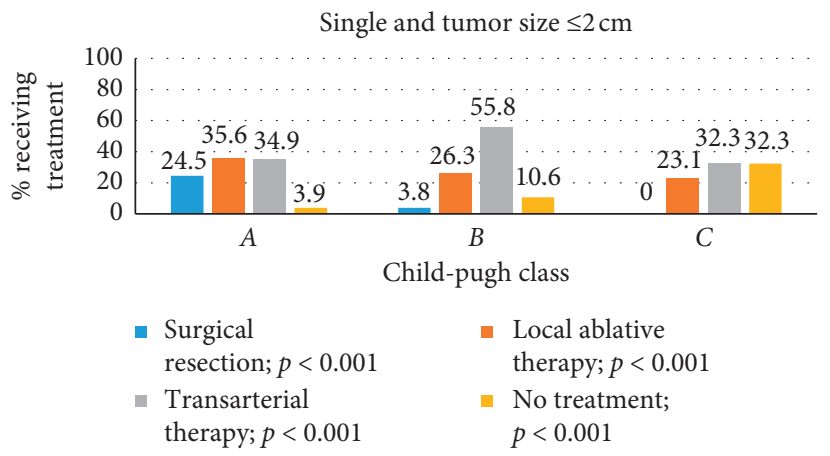

(a)

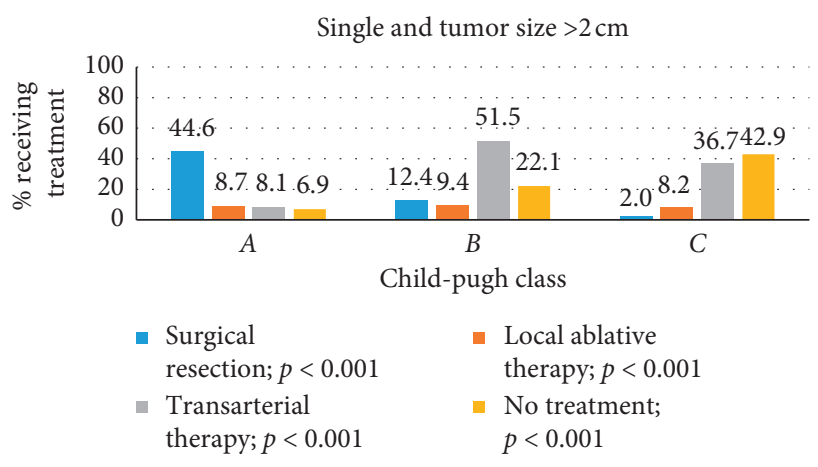

(b)

Figure 2: Proportion of the treatments performed for a single lesion according to Child-Pugh class. (a) Tumor size $\leq 2 \mathrm{~cm}$ for surgical resection, local ablative therapy, transarterial therapy, and no treatment (all $p<0.001$ ). (b) Tumor size $>2 \mathrm{~cm}$ for surgical resection, local ablative therapy, transarterial therapy, and no treatment (all $p<0.001)$.

(Table 3). The rate of application of systemic chemotherapy did not change significantly in both age and CPC groups over $10 \%$ ( $p=0.292$ and $p=0.235$, respectively).

In particular, the proportion of patients with no treatment significantly increased with increasing age $(29.3 \%$ vs. $34.7 \%$ vs. $46.4 \% ;<59,60-69$ and $\geq 70, p=0.001)$ and worse CPC (17.3\% vs. $46.8 \%$ vs. $75.0 \% ; A, B$ and $C, p<0.001)$ (Table 3 and Figure 3).

\section{Discussion}

This study examined the treatment preference for HCC with regarding aging and liver function. The Korean cohort showed that cancer treatments were affected by these conditions, which could be related to the fragility of HCC management. Transarterial therapy was preferred to surgical resection in patients with single lesions, and no treatment in our study was preferred for PVT in the elderly and those with worse liver function.

Surgical resection and RFA are recommended by various guidelines for single-lesion HCC [1-6], and TACE is considered optional according to the tumor location and medical comorbidity $[4,6]$. TACE could also be used in specific situations such as the use of transplantation as bridging therapy [3]; furthermore, RT, including stereotactic body radiotherapy, is another option for single lesions $[1,4]$. However, except for groups $<60$ years, CPC $A$, and $>2 \mathrm{~cm}$ tumor size, TACE was favored in the actual practice of Korean society; in other words, TACE was more frequently used than the recommendations of published guidelines. In a Western survey from France, $81 \%$ and $64 \%$ of intervention radiologists applied TACE in BCLC A and in combination with other therapies, respectively [12]. Despite the actual outcomes, it should be first considered that surgical resections obtain greater long-term overall survival (OS) and recurrence-free survival than the combination of TACE plus RFA in a meta-analysis [13]. However, in salvage therapy after initial hepatectomy, TACE plus RFA was comparable to repeated surgical resection for OS and morbidity after propensity score matching (PSM) [14]. In another PSM study, TACE plus RFA had better OS than the monotherapy of RFA or TACE in patients with a tumor size $<3 \mathrm{~cm}$ [15]. In addition, TACE was preferred to systematic chemotherapy in PVT because of the policies of the Korean National Insurance that do not allow changes to TACE after the use of systematic emerging therapies such as sorafenib and, at the 
TABle 3: Treatment pattern change by age and the Child-Pugh classification in PVT-positive patients.

\begin{tabular}{|c|c|c|c|c|}
\hline \multirow{2}{*}{ Treatment $n=605$} & \multicolumn{4}{|c|}{ Age (years) } \\
\hline & $\leq 59$ & $60-69$ & $\geq 70$ & $p$ value \\
\hline Surgical resection & $16(4.6 \%)$ & $5(3.5 \%)$ & $1(0.9 \%)$ & 0.081 \\
\hline $\begin{array}{l}\text { Liver } \\
\text { transplantation }\end{array}$ & $3(0.9 \%)$ & $3(2.1 \%)$ & $0(0.0 \%)$ & 0.748 \\
\hline $\begin{array}{l}\text { Local ablative } \\
\text { therapy }\end{array}$ & $3(0.9 \%)$ & $1(0.7 \%)$ & $1(0.9 \%)$ & 0.996 \\
\hline terial & $\begin{array}{c}160 \\
(45.6 \%)\end{array}$ & $\begin{array}{c}64 \\
(44.4 \%)\end{array}$ & $\begin{array}{c}43 \\
(39.1 \%)\end{array}$ & 0.262 \\
\hline $\begin{array}{l}\text { ic } \\
\text { herapy }\end{array}$ & $54(15.4 \%)$ & $15(10.4 \%)$ & $\begin{array}{c}14 \\
(12.7 \%)\end{array}$ & 0.292 \\
\hline Radiation & $12(3.4 \%)$ & $6(4.2 \%)$ & $0(0.0 \%)$ & 0.137 \\
\hline No treatment & $\begin{array}{c}103 \\
(29.3 \%)\end{array}$ & $\begin{array}{c}50 \\
(34.7 \%)\end{array}$ & $\begin{array}{c}51 \\
(46.4 \%)\end{array}$ & 0.001 \\
\hline \multirow{2}{*}{$n=605$} & \multicolumn{4}{|c|}{ Child-Pugh classification } \\
\hline & A & $B$ & C & \\
\hline Surgical resection & $20(6.3 \%)$ & $2(0.9 \%$ & $0(0.0 \%)$ & $<0.001$ \\
\hline $\begin{array}{l}\text { Liver } \\
\text { transplantation }\end{array}$ & $2(0.6 \%)$ & $2(0.9 \%)$ & $2(3.8 \%)$ & 0.094 \\
\hline $\begin{array}{l}\text { Local ablative } \\
\text { therapy }\end{array}$ & $4(1.3 \%)$ & $1(0.4 \%)$ & $0(0.0 \%)$ & 0.211 \\
\hline $\begin{array}{l}\text { Transarterial } \\
\text { therapy }\end{array}$ & $\begin{array}{c}178 \\
(56.0 \%)\end{array}$ & $81(34.5 \%)$ & $8(15.4 \%)$ & $<0.001$ \\
\hline $\begin{array}{l}\text { Systemic } \\
\text { chemotherapy }\end{array}$ & $46(14.5 \%)$ & $34(14.5 \%)$ & $3(5.8 \%)$ & 0.235 \\
\hline Radiation therapy & $13(4.1 \%)$ & $5(2.1 \%)$ & $0(0.0 \%)$ & 0.060 \\
\hline No treatment & $55(17.3 \%)$ & $\begin{array}{c}110 \\
(46.8 \%)\end{array}$ & $\begin{array}{c}39 \\
(75.0 \%)\end{array}$ & $<0.001$ \\
\hline
\end{tabular}

PVT, portal vein tumor thrombosis.

\begin{tabular}{|l|c|c|c|c|c|}
\hline Age CPC & 5 & 6 & 7 & $8-9$ & $\geq 10$ \\
\hline 59 & 14.9 & 10.1 & 39.2 & 49.3 & 65.6 \\
\cline { 1 - 1 } $60-64$ & 11.1 & 18.8 & 40.0 & 50.0 & 87.5 \\
\cline { 1 - 1 } $65-59$ & 9.5 & 31.3 & 27.3 & 52.9 & 100.0 \\
\cline { 1 - 1 } $70-74$ & 17.6 & 30.0 & 31.3 & 55.6 & 100.0 \\
\cline { 1 - 1 }$\geq 75$ & 25.0 & 60.0 & 70.0 & 66.7 & 100.0 \\
\hline
\end{tabular}

FIGURE 3: Proportion of patients who did not receive any treatment in the PVT-positive group and with increasing age and a worse Child-Pugh score, the proportion of patients in whom no treatment was increased. The degree of the ratio was expressed in gradation.

end point of our study, did not cover the full costs of these agents. Finally, the solid multidisciplinary approach with the intervention radiologists and hepatologists in each institution had a role in the patients' initial choice of treatment for PVT. In a meta-analysis, TACE plus sorafenib improved the OS, time to progression, and objective response rate with rare moderate adverse events compared to TACE alone [16]. Another PSM study showed similar outcomes with a median 13 months of 1-year OS in the group of TACE plus sorafenib (7 months in group of TACE alone) [17]. Interestingly, a recent Korean randomized control study showed that TACE plus RT was better than sorafenib alone in terms of objective response rate $(33.3 \%$ vs. $2.2 \%)$ and median time to progression (31.0 weeks vs. 11.7 weeks) for macroscopic vascular invasion tumors [18]. A certain rate of TACE in our cohort would be combined with RT when estimating the previous Korean cohort study of RT in PVT, which showed that more than half of the RT was performed with previous TACE [19].

The liver ages with changes in hepatic weight, volume, and blood flow, including bile flow and Kupffer cell function [20]. Several studies have reported that surgical resection is feasible with comparable survival benefit and safety [21-23]. However, a recent meta-analysis showed that the elderly had a slightly lower 5 -year OS (55 months vs. 58 months) than younger patients, with an increased hospital mortality of $3.0 \%$ (1.2\% in younger patients) [24]. Previous systematic reviews have demonstrated that there is no significant difference in morbidity between RFA, TACE, and sorafenib $[20,25]$. However, it is important to consider the selection bias that retrospective studies would induce in the absence of randomized control studies regarding the elderly. Thus, a comprehensive geriatric assessment and close examination of liver function before using definitive therapies could better advise the decision of treatment.

In South Korea, HCC primarily develops in patients with hepatitis B and cirrhotic liver. On the other hand, hepatitis C virus- (HCV-) related liver cirrhosis and $\mathrm{HCC}$ is a major risk factor in the Western world and Japan [26]. There are many differences in characteristics between HBV and HCV in a Korean Central Cancer Registry study. However, there have been reports of studies that did not show differences depending on the cause of the virus when corrected according to the stage [8]. Since one meta-analysis has shown that the risk of recurrence and survival vary widely in patients successfully treated with $\mathrm{HCV}$-associated HCC, a careful approach should be taken in the treatment of $\mathrm{HCV}$ patients [27].

In general, surgeons from Eastern countries adopt a more aggressive surgical approach toward HCC compared to the West in terms of surgical resection or liver transplantation [1-6, 9]. This is because HCC in Eastern patients with $\mathrm{HBV}$ occurs more frequently in younger patients and in those who have less severe cirrhosis as opposed to Western patients with HCV, who frequently present with decompensated liver disease. Compared to the West, transarterial therapy is adopted more often than sorafenib for BCLC C patients in Asian countries [9]. Across all stages, first, HCC treatment was most frequently transarterial therapy in North America, Europe, China, and South Korea, percutaneous ethanol injection or radiofrequency ablation in Japan, and resection in Taiwan [26].

In CPC A patients, direct therapy of surgical resection, RFA, TACE, and RT is affordable. The management of patients with CPC B remains a clinical challenge as any intervention might be offset by liver function deterioration [28]. In the survival assessment analyzed using the Korean Central Cancer Registry, the 5-year survival rates of CPC stage $\mathrm{A}, \mathrm{B}$, and $\mathrm{C}$ patients were $52.1 \%, 16.6 \%$, and $11.1 \%$, respectively [29]. When considering the use of sorafenib in advanced HCC with CPC B, it is important to conduct careful evaluation of individual patients because the incidence of serious adverse events (AEs) was higher in CPC B patients with a score of $8-9$ compared with 7 in GIDEON 
study [30]. However, the overall incidence of drug-related AEs leading to discontinuation was similar between CPC $A$ and $B$ patients $(17 \%$ vs. $21 \%)$. In subgroup analysis of Chinese GIDEON, sorafenib was tried in CPC B, which showed that the safety was similar to that in CPC A; however, the OS was worse [31]. In a meta-analysis, the main observations for safety and OS were not significantly different to those in a previous report [32]. In addition, there are reports that sorafenib-related AEs have prognostic significance in OS and/or time to progression (TTP), so this needs to be interpreted carefully [33]. For TACE, the complication was increased in CPC B with a hazard ratio of 2.1 (95\% CI, 1.1-4.1) [34]. Furthermore, the albumin-bilirubin score was demonstrated to be a strong predictor of liver decompensation after surgical resection, TACE, and sorafenib [35]. For RT, approximately $20 \%$ of radiationinduced liver disease was developed with a median biological effective dose of $56 \mathrm{~Gy}$ in CPC $B$ [36]. In most guidelines, the best supportive care was strongly recommended for $\mathrm{CP}$ score 9 or CPC C. Our study showed that $36.3 \%$ of patients with single tumors and $75.0 \%$ of patients with PVT received no further treatment in CPC C.

The cohort of KCCR obtained nationwide populationbased data; however, it has limitations regarding conducting customized studies for specific subjects. First, in the current study, the details of subsequent managements combined with initial management were not presented; therefore, TACE will carry greater weighting in the final analysis. Second, we lacked specific information related to fragile conditions such as comorbidity, and only chronological age was assessed in our study. Thirdly, although our study excluded patients with PVT and extrahepatic metastases to evaluate single lesions, some conditions for conducting surgical resection and RFA could have been missed. Lastly, the category of "no treatment" included a minority of patients who visited other hospitals to gather a second opinion, after which they may have chosen further treatment.

\section{Conclusions}

Therapeutic decision-making for HCC is markedly affected by age and liver function in the Korean society. Under the difficult circumference to conduct randomized controlled studies for these fragile patients, previous studies and our own experiences suggest that our observations will assist decision making in actual practice. Experts' consensus would be necessary to further guide the management of elderly patients and those with unfavorable liver function.

\section{Data Availability}

The data used to support the findings of this study are included within the article and are available from the corresponding author upon request.

\section{Conflicts of Interest}

The authors declare that they have no conflicts of interest.

\section{Acknowledgments}

This study was supported by a Korea University Ansan Hospital grant (O1903621 and K2010971). The funding body had no role in the study design, data collection, data analysis, decision to publish, or preparation of the manuscript.

\section{References}

[1] A. B. Benson, M. I. D’Angelica, D. E Abbott et al., "Guidelines insights: hepatobiliary cancers, version 2.2019," Journal of the National Comprehensive Cancer Network: JNCCN, vol. 17, no. 4, pp. 302-310, 2019.

[2] European Association for the Study of the Liver, "EASL clinical practice guidelines: management of hepatocellular carcinoma," Journal of Hepatology, vol. 69, no. 1, pp. 182-236, 2018.

[3] J. K. Heimbach, L. M. Kulik, and R. S. Finn, et al., AASLD guidelines for the treatment of hepatocellular carcinoma," Hepatology, vol. 67, no. 1, pp. 358-380, 2018.

[4] Korean Sirlin and National Cancer Center, "Korean liver cancer association-national cancer center Korea practice guidelines for the management of hepatocellular carcinoma," Gut Liver, vol. 13, no. 3, pp. 227-299, 2018.

[5] A. Vogel, A. Cervantes, I. B. Chau et al., "Hepatocellular carcinoma: ESMO Clinical Practice Guidelines for diagnosis, treatment and follow-up," Annals of Oncology, vol. 29, no. 4, pp. iv238-iv255, 2018.

[6] M. Daniele, A.-L. Cheng, N. M. Kokudo et al., "Asia-Pacific clinical practice guidelines on the management of hepatocellular carcinoma: a 2017 update," Hepatology International, vol. 11, no. 4, pp. 317-370, 2017.

[7] K.-W. Kudo, Y.-J. Won, H.-J. Kong, and E. S. Lee, "Cancer statistics in Korea: incidence, mortality, survival, and prevalence in 2016," Cancer Research and Treatment, vol. 51, no. 2, pp. 417-430, 2019.

[8] D. H. Sinn, G. Y. Gwak, J. Cho, S. W. Paik, and B. C. Yoo, "Comparison of clinical manifestations and outcomes between hepatitis B virus-and hepatitis C virus-related hepatocellular carcinoma: analysis of a nationwide cohort," PLoS One, vol. 9, no. 11, Article ID e112184, 2014.

[9] S. P. Choo, W. L. Tan, B. K. P. Goh, W. M. Tai, and A. X. Zhu, "Comparison of hepatocellular carcinoma in Eastern versus Western populations," Cancer, vol. 122, no. 22, pp. 3430-3446, 2016.

[10] B. H. Kim and J.-W. Park, "Epidemiology of liver cancer in South Korea," Clinical and Molecular Hepatology, vol. 24, no. 1, pp. 1-9, 2018.

[11] B. H. Kim, Y.-S. Lim, and E.-Y. Kim, et al., Temporal improvement in survival of patients with hepatocellular carcinoma in a hepatitis B virus-endemic population," Journal of Gastroenterology and Hepatology, vol. 33, no. 2, pp. 475-483, 2018.

[12] A. Kong, J. P. Tasu, H. Kobeiter, J. M. Bartoli, J. P. Pelage, and B. Guiu, "Transarterial chemoembolization (TACE) in the management of hepatocellular carcinoma: results of a French national survey on current practices," Diagnostic and Interventional Imaging, vol. 99, no. 9, pp. 527-535, 2018.

[13] P.-S. Yi, M. Huang, M. Zhang, L. Xu, and M.-Q. Xu, "Comparison of transarterial chemoembolization combined with radiofrequency ablation therapy versus surgical resection for early hepatocellular carcinoma," The American Surgeon, vol. 84, no. 2, pp. 282-288, 2018. 
[14] Z. Peng, M. Wei, S. Chen et al., "Combined transcatheter arterial chemoembolization and radiofrequency ablation versus hepatectomy for recurrent hepatocellular carcinoma after initial surgery: a propensity score matching study," European Radiology, vol. 28, no. 8, pp. 3522-3531, 2018.

[15] M. J. Lin, S. H. Bae, J. S. Lee et al., "Combination transarterial chemoembolization and radiofrequency ablation therapy for early hepatocellular carcinoma," The Korean Journal of Internal Medicine, vol. 31, no. 2, pp. 242-252, 2016.

[16] X. Lee, K. Wang, M. G. Wang, X. Ye, M. Wu, and S. Cheng, "Transarterial chemoembolization (TACE) combined with sorafenib versus TACE for hepatocellular carcinoma with portal vein tumor thrombus: a systematic review and metaanalysis," Oncotarget, vol. 8, no. 17, pp. 29416-29427, 2017.

[17] J. Yang, X. Yin, B. Tang et al., "Transarterial chemoembolization (TACE) combined with sorafenib in treatment of HBV background hepatocellular carcinoma with portal vein tumor thrombus: a propensity score matching study," Biomed Research International, vol. 2019, Article ID 2141859, 6 pages, 2019.

[18] S. M. Yoon, B.-Y. Ryoo, S. J. Lee et al., "Efficacy and safety of transarterial chemoembolization plus external beam radiotherapy vs sorafenib in hepatocellular carcinoma with macroscopic vascular invasion," JAMA Oncology, vol. 4, no. 5, pp. 661-669, 2018.

[19] J. H. Kim, S. M. Yoon, H. C. Park et al., "Radiotherapeutic strategies for hepatocellular carcinoma with portal vein tumour thrombosis in a hepatitis B endemic area," Liver International, vol. 37, no. 1, pp. 90-100, 2017.

[20] A. Kim, K. Koike, and H. Nishino, "Clinical features and prognosis of elderly patients with hepatocellular carcinoma not indicated for surgical resection," Geriatrics \& Gerontology International, vol. 17, no. 2, pp. 189-201, 2017.

[21] K.-F. Hsu, J.-C. Yu, C.-W. Yang et al., "Long-term outcomes in elderly patients with resectable large hepatocellular carcinoma undergoing hepatectomy," Surgical Oncology, vol. 27, no. 3, pp. 595-601, 2018.

[22] H. Chen, L. Liang, H. Wang et al., "Multicenter analysis of long-term oncologic outcomes of hepatectomy for elderly patients with hepatocellular carcinoma," $H P B$ (Oxford), vol. 22, no. 9, 2020.

[23] X. Yu, Y. C. Yan, G. Chen, and H. Yu, "The efficacy and safety of totally laparoscopic hepatectomy for non-cirrhotic hepatocellular carcinoma in the elderly," BMC Surgery, vol. 18, no. 1, p. 118, 2018.

[24] L.-Y. Zhao, R.-R. Huo, X. Xiang et al., "Hepatic resection for elderly patients with hepatocellular carcinoma: a systematic review of more than 17,000 patients," Expert Review of Gastroenterology \& Hepatology, vol. 12, no. 10, pp. 1059-1068, 2018.

[25] E. Torzilli, H. A. Cho, C. H. Jun, H. J. Kim, S. B. Cho, and S. K. Choi, "A review of hepatocellular carcinoma in elderly patients focused on management and outcomes," In Vivo, vol. 33, no. 5, pp. 1411-1420, 2019.

[26] J. W. Park, M. Chen, M. Colombo et al., "Global patterns of hepatocellular carcinoma management from diagnosis to death: the BRIDGE Study," Liver International, vol. 35, no. 9, pp. 2155-2166, 2015.

[27] G. Roberts, S. Petta, M. Barbàra et al., "A meta-analysis of single HCV-untreated arm of studies evaluating outcomes after curative treatments of HCV-related hepatocellular carcinoma," Liver International, vol. 37, no. 8, pp. 1157-1166, 2017.
[28] A. Missale and L. Bolondi, "Non-transplant therapies for patients with hepatocellular carcinoma and Child-PughTurcotte class B cirrhosis," The Lancet Oncology, vol. 18, no. 2, pp. e101-e112, 2017.

[29] J. S. Yoon, H. A. Lee, J. Y. Park et al., "Hepatocellular carcinoma in Korea between 2008 and 2011: an analysis of Korean nationwide cancer registry," Journal of Liver Cancer, vol. 20, no. 1, pp. 41-52, 2020.

[30] J. A. Kim, M. Kudo, A. P. Venook et al., "Observational registry of sorafenib use in clinical practice across Child-Pugh subgroups: the GIDEON study," Journal of Hepatology, vol. 65, no. 6, pp. 1140-1147, 2016.

[31] S. L. Ye, J. Yang, P. Bie et al., "Safety assessment of sorafenib in Chinese patients with unresectable hepatocellular carcinoma: subgroup analysis of the GIDEON study," BMC Cancer, vol. 18 , no. 1 , p. $247,2018$.

[32] M. G. McNamara, A. E. Slagter, C. M. Nuttall et al., "Sorafenib as first-line therapy in patients with advanced Child-Pugh B hepatocellular carcinoma-a meta-analysis," European Journal of Cancer, vol. 105, pp. 1-9, 2018.

[33] A. Frizziero, S. Marinelli, G. Negrini, S. Menetti, F. Benevento, and L. Bolondi, "Prognostic significance of adverse events in patients with hepatocellular carcinoma treated with sorafenib," Therapeutic Advances in Gastroenterology, vol. 9, no. 2, pp. 240-249, 2016.

[34] K. Han, J. H. Kim, H. M. Yoon et al., "Transcatheter arterial chemoembolization for infiltrative hepatocellular carcinoma: clinical safety and efficacy and factors influencing patient survival," Korean Journal of Radiology, vol. 15, no. 4, pp. 464-471, 2014.

[35] D. J. Kim, R. Sharma, E. Allara et al., "The ALBI grade provides objective hepatic reserve estimation across each BCLC stage of hepatocellular carcinoma," Journal of Hepatology, vol. 66, no. 2, pp. 338-346, 2017.

[36] S. H. Yen, H. C. Park, S. M. Yoon et al., "Treatment outcome after fractionated conformal radiotherapy for hepatocellular carcinoma in patients with child-pugh classification B in Korea (KROG 16-05)," Cancer Research and Treatment, vol. 51, no. 4, pp. 1589-1599, 2019. 